\title{
Ly-6Chi monocytes dominate hypercholesterolemia-associated monocytosis and give rise to macrophages in atheromata
}

\author{
Filip K. Swirski, 1,2,3,4 Peter Libby, ${ }^{2,3,4}$ Elena Aikawa, ${ }^{1}$ Pilar Alcaide, ${ }^{3}$ \\ F. William Luscinskas, ${ }^{3}$ Ralph Weissleder, ${ }^{1,4}$ and Mikael J. Pittet ${ }^{1}$
}

\begin{abstract}
${ }^{1}$ Center for Molecular Imaging Research, Massachusetts General Hospital, Harvard Medical School, Charlestown, Massachusetts, USA. ${ }^{2}$ Cardiovascular Division, Department of Medicine, and ${ }^{3}$ Center for Excellence in Vascular Biology, Department of Pathology, Brigham and Women's Hospital, Boston, Massachusetts, USA. ${ }^{4}$ Donald W. Reynolds Cardiovascular Clinical Research Center, Harvard Medical School, Boston, Massachusetts, USA.
\end{abstract}

\begin{abstract}
Macrophage accumulation participates decisively in the development and exacerbation of atherosclerosis. Circulating monocytes, the precursors of macrophages, display heterogeneity in mice and humans, but their relative contribution to atherogenesis remains unknown. We report here that the Ly- $6 \mathrm{C}^{\text {hi }}$ monocyte subset increased dramatically in hypercholesterolemic apoE-deficient mice consuming a high-fat diet, with the number of Ly-6 $\mathrm{Chi}^{\text {hi }}$ cells doubling in the blood every month. Ly-6 $\mathrm{Chi}^{\mathrm{hi}}$ monocytes adhered to activated endothelium, infiltrated lesions, and became lesional macrophages. Hypercholesterolemia-associated monocytosis (HAM) developed from increased survival, continued cell proliferation, and impaired $\mathrm{Ly}-6 \mathrm{C}^{\text {hi }}$ to $\mathrm{Ly}-6 \mathrm{C}^{\mathrm{lo}}$ conversion and subsided upon statin-induced cholesterol reduction. Conversely, the number of Ly- $6 \mathrm{C}^{\text {lo }}$ cells remained unaffected. Thus, we believe that $\mathrm{Ly}-6 \mathrm{C}^{\mathrm{hi}}$ monocytes represent a newly recognized component of the inflammatory response in experimental atherosclerosis.
\end{abstract}

\section{Introduction}

During atherogenesis, an inflammatory process, leukocytes and lipids accumulate in the aortic intima $(1,2)$. Lipid-rich macrophages, known as foam cells in atheromata, secrete inflammatory mediators that stimulate smooth muscle cell migration and proliferation and participate in plaque development and rupture as well as thrombosis. Serum C-reactive protein and other molecular mediators of inflammation have broadened our understanding of the disease by illustrating that peripheral blood can afford valuable prognostic information $(3,4)$. Leukocyte counts rise in atherosclerotic patients. Yet, the extent to which circulating leukocyte subsets reflect the inflammatory response during atherogenesis remains less defined (5-9). This study tested the hypothesis that leukocyte heterogeneity in atherosclerosis could provide novel markers of and mechanistic insights into atherogenesis.

Prevailing concepts view monocytes as intermediary cells that continuously develop in the bone marrow, circulate in the bloodstream, and migrate unselected into tissue, where they become macrophages, dendritic cells, or other tissue descendants (10-12). Studies in atherosclerotic mice have shown that bone marrowderived circulating monocytes populate atherosclerotic lesions (13-17), and many studies support an active role for monocytes/ macrophages in atherosclerosis (reviewed in refs. 1,2). The appreciation of monocyte heterogeneity (18-20) has led to the hypothesis that monocytes commit for specific functions while still in the circulation. Indeed, both human and mouse monocytes fall into at least 2 phenotypically distinct subsets: Ly-6Chi (which are also phenotypically $\mathrm{Gr}-1^{+} \mathrm{CCR} 2^{+} \mathrm{CX} 3 \mathrm{CR} 1^{\mathrm{lo}}$ ) and $\mathrm{Ly}-6 \mathrm{C}^{\mathrm{lo}}$ (which are

Nonstandard abbreviations used: AcLDL, acetylated low-density lipoprotein; CCR2, C-C motif chemokine receptor 2; CD62L, CD62 ligand; HAM, hypercholesterolemia-associated monocytosis; MHEC, mouse heart EC.

Conflict of interest: The authors have declared that no conflict of interest exists. Citation for this article: J. Clin. Invest. 117:195-205 (2007). doi:10.1172/JCI29950. also phenotypically Gr-1-CCR2-CX3CR1 $1^{\text {hi }}$ ) mouse monocytes correspond to human $\mathrm{CD} 14^{\mathrm{hi}} \mathrm{CD} 16^{-}$and $\mathrm{CD} 14^{+} \mathrm{CD} 16^{+}$monocytes, respectively $(19,21-24)$. Ly-6Chi cells selectively populate sites of experimentally induced inflammation, while their Ly- $6 \mathrm{C}^{\text {lo }}$ counterparts can enter lymphoid and nonlymphoid tissues under homeostatic conditions (24).

This study explored Ly- $6 \mathrm{C}^{\text {hi }}$ and Ly- $6 \mathrm{C}^{\mathrm{lo}}$ monocytes in atherosclerotic mice. The results show that hypercholesterolemia induced a surprisingly profound expansion of blood Ly- $6 \mathrm{C}^{\text {hi }}$ but not Ly- $6 \mathrm{C}^{\text {lo }}$ monocytes, a process we termed hypercholesterolemia-associated monocytosis (HAM). Our results also establish a direct link between circulating Ly-6Chi monocytes and lesional macrophages.

\section{Results}

Hypercholesterolemic apoE $E^{-1-}$ mice undergo gradual and systemic monocytosis of the $L y-6 C^{h i}$ subset. To test the hypothesis that high-fat feeding alters the repertoire of circulating monocytes, we analyzed peripheral blood mononuclear cells from C57BL/6 wild-type (referred to as apo $\left.\mathrm{E}^{+/+}\right)$and $\mathrm{apo} \mathrm{E}^{-/-}$mice that consumed either regular chow or Western diet (high in cholesterol and fat) for 25 weeks. Monocytes were defined as $\mathrm{CD} 11 \mathrm{~b}^{\text {hi }} \mathrm{CD} 90^{\mathrm{lo}} \mathrm{B} 220^{\mathrm{lo}} \mathrm{CD} 49 \mathrm{~b}^{\mathrm{lo}} \mathrm{NK} 1.1^{\mathrm{lo}} \mathrm{Ly}-6 \mathrm{G}^{\mathrm{lo}}$ mononuclear cells by flow cytometry, as previously reported (16), and further divided into $\mathrm{Ly}-6 \mathrm{C}^{\mathrm{hi}}$ and $\mathrm{Ly}-6 \mathrm{C}^{\mathrm{lo}}$ fractions (Figure $1 \mathrm{~A}$ ). apoE $-/$ mice on Western diet had a 4-fold increase of total circulating monocytes when compared with the same mice on chow (Figure 1B). Monocytosis in apoE $\mathrm{E}^{-/-}$mice on Western diet resulted from a 14-fold increase of the Ly-6Chi subset (Figure 1C), whereas the Ly- $6 \mathrm{C}^{\mathrm{lo}}$ population remained unchanged (Figure 1D). Consumption of a Western diet increased slightly the number of total circulating leukocytes in apoE $\mathrm{E}^{-/-}$mice (mean $\pm \mathrm{SEM}$, chow, $3.0 \pm 0.5 \times 10^{6} \mathrm{cells} / \mathrm{ml}$; Western diet, $3.9 \pm 0.4 \times 10^{6} \mathrm{cells} / \mathrm{ml}$; Figure $1 \mathrm{E}$ ). Blood smear counts showed that this increase arose primarily from monocytes (chow, $0.14 \pm 0.03 \times 10^{6}$ cells $/ \mathrm{ml}$; Western diet, $0.94 \pm 0.11 \times 10^{6} \mathrm{cell} / \mathrm{s} / \mathrm{ml}$ ), although granulocytes also increased (chow, 
A

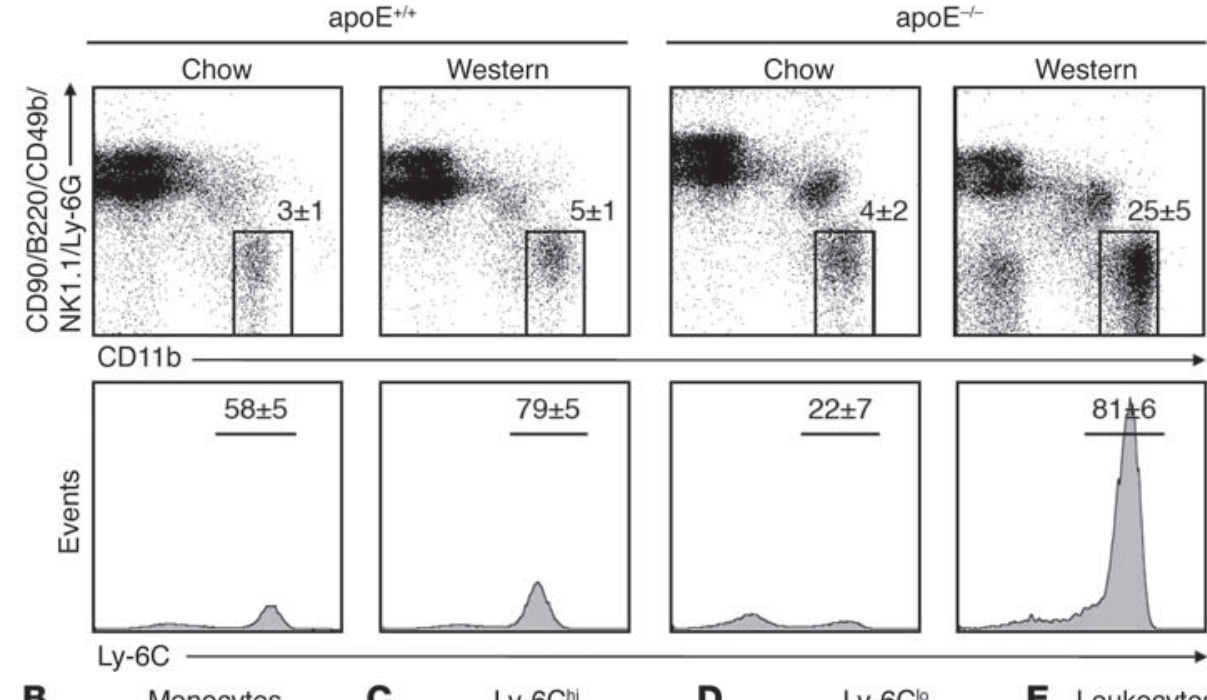

B Monocytes
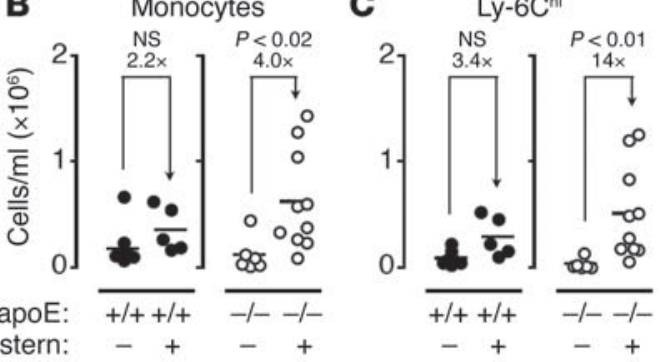

D

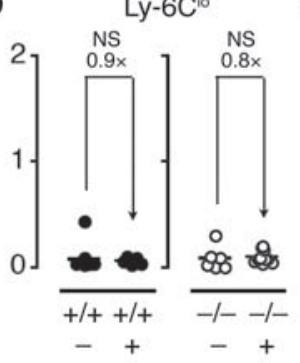

Leukocytes

$\mathbf{F}$

$\frac{\mathrm{apoE}^{+/+}}{\text {Western }} \frac{\mathrm{apoE}^{-/-}}{\text {Chow }}$ Western
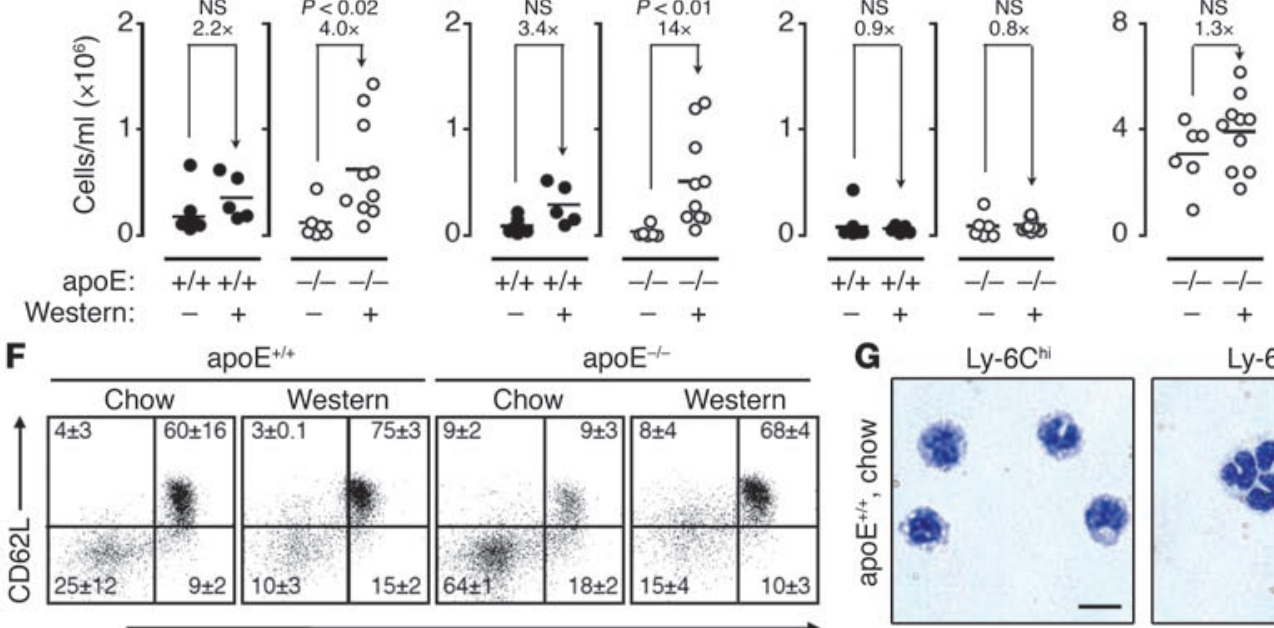

$-+$

Ly-6C
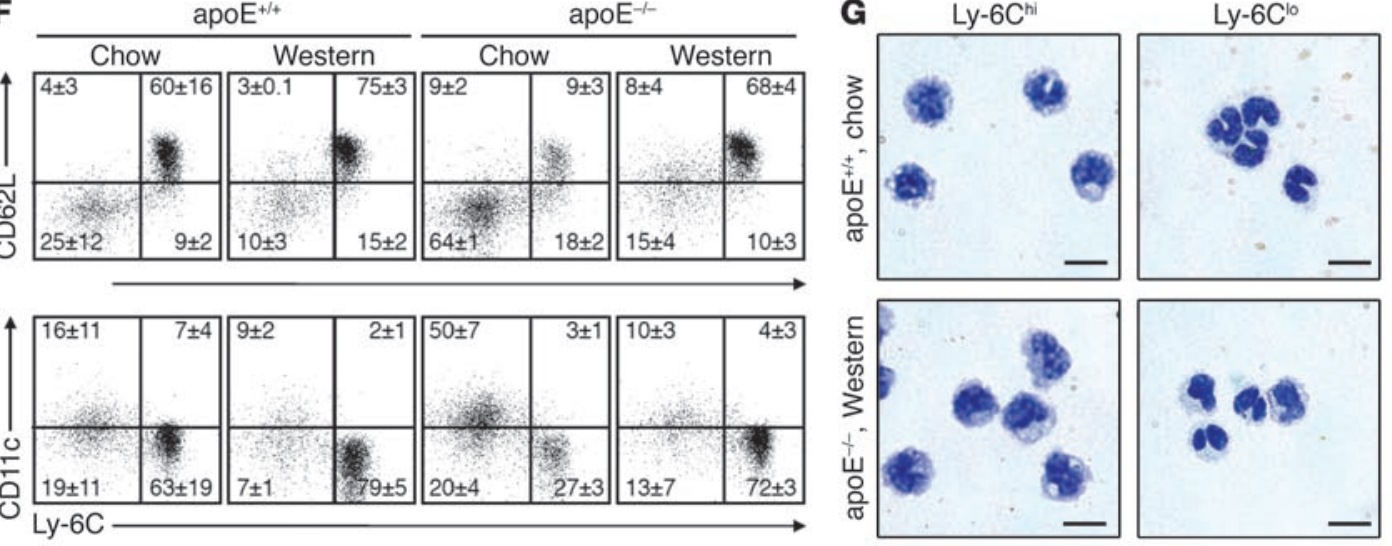

Figure 1

Hypercholesterolemia induces peripheral blood Ly-6Chi monocytosis. (A) Mononuclear cells from blood of apoE ${ }^{+/+}$and apoE ${ }^{-/-}$mice consuming either chow or Western diet were stained with anti-CD11b, -CD90, -B220, -CD49b, -NK1.1, -Ly-6G, and -Ly-6C mAbs. Living cells were gated to determine presence and percentage of $\mathrm{CD} 11 \mathrm{~b}^{\text {hi }} \mathrm{CD} 90^{\mathrm{lo}} \mathrm{B} 220^{\mathrm{lo}} \mathrm{CD} 49 \mathrm{~b}^{\mathrm{lo}} \mathrm{NK} 1.1^{\mathrm{lo}} \mathrm{Ly}-6 \mathrm{G}$ lo monocytes (top row) and further divided into $\mathrm{Ly}-6 \mathrm{C}^{\mathrm{hi}}$ and $\mathrm{Ly}-6 \mathrm{C}^{\mathrm{lo}}$ subsets (bottom row). Representative dot plots and histograms from individual mice are depicted. Percentages of cells are shown as mean \pm SEM. (B) Total blood monocytes in apoE $\mathrm{E}^{+/+}$and apoE $\mathrm{E}^{-/-}$mice consuming either Western diet (+) or chow (-). (C) Total blood Ly-6Chi monocytes. (D) Total blood Ly-6Clo monocytes. (E) Total peripheral blood leukocytes. (F) Representative dot plots depicting expression of CD62L and CD11c among Ly-6Chi and Ly-6Clo monocytes. Percentages of cells in each quadrant are shown as mean \pm SEM. (G) Representative cytospin preparations of purified blood Ly- $6 \mathrm{C}^{\mathrm{hi}}$ and $\mathrm{Ly}-6 \mathrm{C}^{\mathrm{l}}$ monocytes in $\mathrm{apo} \mathrm{E}^{+/+}$mice on chow and apoE ${ }^{-/-}$mice on Western diet. Scale bar: $10 \mu \mathrm{m}$. Student's $t$ test was used. Results are representative of 8 independent experiments with 5-14 mice per group.

$0.27 \pm 0.03 \times 10^{6}$ cells $/ \mathrm{ml}$; Western diet, $0.96 \pm 0.11 \times 10^{6}$ cells $\left./ \mathrm{ml}\right)$ and lymphocytes decreased slightly (chow, $2.4 \pm 0.6 \times 10^{6}$ cells $/ \mathrm{ml}$; Western diet, $2.0 \pm 0.2 \times 10^{6}$ cells $\left./ \mathrm{ml}\right)$. As expected $(25,26)$, apoE $\mathrm{E}^{-/}$mice on Western diet had increased serum cholesterol levels $(479 \pm 20 \mathrm{mg} / \mathrm{dl})$ when compared with apoE $\mathrm{E}^{-/-}$mice on chow $(286 \pm 25 \mathrm{mg} / \mathrm{dl})$. Macroscopic and histologic examination of aortas revealed fatty streaks and fibrous plaque lesions in the root and descending aorta of $\mathrm{apoE}^{-/-}$mice regardless of diet. Lesions were identified along the entire aorta in older mice (i.e., mice that consumed Western diet for 50 weeks; data not shown). apoE ${ }^{-/-}$mice consuming Western diet had 3-5 times more extended and widespread atherosclerotic lesions than $\mathrm{did}_{\mathrm{apoE}} /-$ mice on chow. 
A
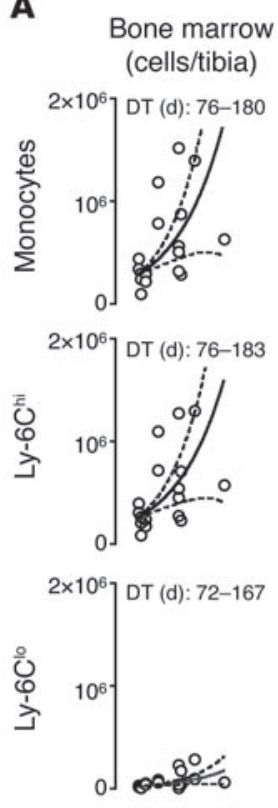

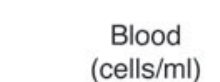

(cells/ml)

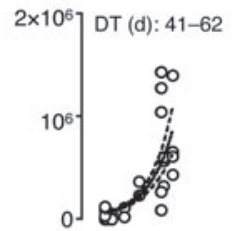

$\left.2 \times 10^{6}\right]$ DT (d) : $33-38$
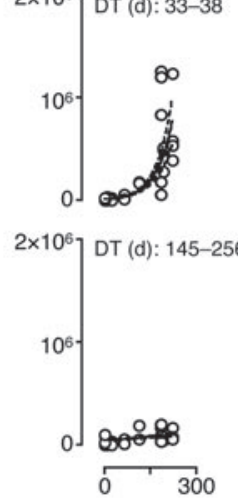

Spleen

(cells/spleen)

$4 \times 10^{7}$ DT (d): $34-40$

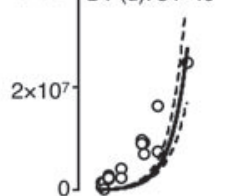

$\left.4 \times 10^{7}\right]$ DT (d): 54-61
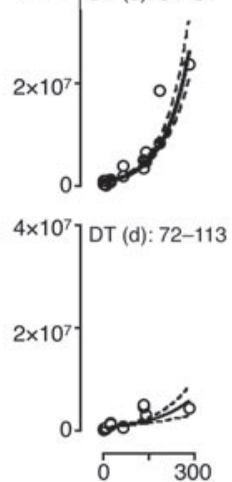

B
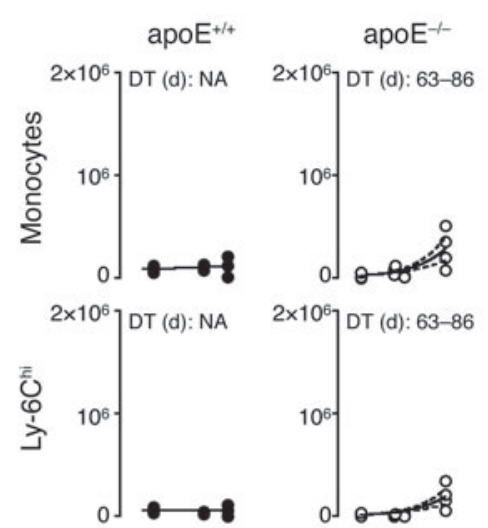

$\left.2 \times 10^{6}\right]$ DT (d): 63-86
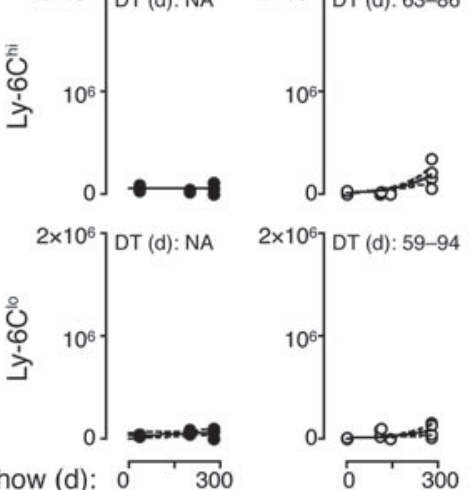

C
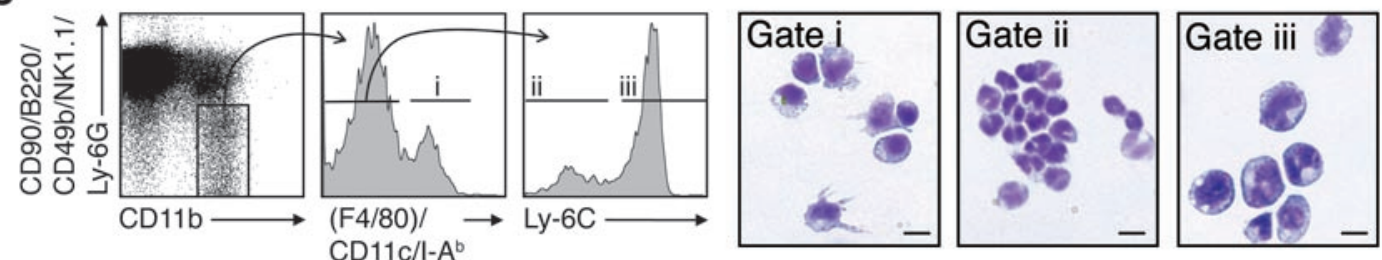

Figure 2

Peripheral blood monocytosis develops over the course of 250 days on an atherogenic diet. (A) Number of total monocytes and Ly-6Chi and Ly- $6 \mathrm{C}^{l 0}$ subtypes in bone marrow, blood, and spleens of apoE ${ }^{-1-}$ mice at various days of Western diet. Statistical analysis was based on an exponential growth curve and known cell numbers on day 0. Curve fit (solid line) and 95\% confidence intervals (dashed lines) are shown. Doubling time (DT) of cell number is shown. (B) The same analysis was conducted with peripheral blood from apoE $\mathrm{E}^{+/+}$and apoE $\mathrm{E}^{-/-}$mice that remained

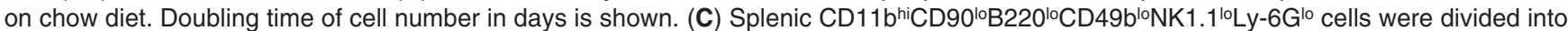

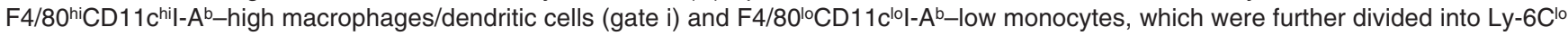
(gate ii) and Ly-6C ${ }^{\text {hi }}$ (gate iii) subsets. These 3 subsets were isolated and stained with HEMA 3 for microscopic analysis. Scale bar: $10 \mu \mathrm{m}$. Results are pooled from 8 independent experiments.

$\mathrm{apoE}^{+/+}$mice fed a Western diet had serum cholesterol levels of $227 \pm 39 \mathrm{mg} / \mathrm{dl}$, lower than those observed in apoE $\mathrm{E}^{-/}$mice on Western diet but higher than those in $\mathrm{apoE}^{+/+}$mice on chow $(101 \pm 10 \mathrm{mg} / \mathrm{dl})$. apoE $\mathrm{E}^{+/+}$mice fed a Western diet did not show a significant increase in the number of circulating monocytes or Ly- $6 \mathrm{C}^{\text {hi }}$ monocytes (Figure 1, B-D) and did not develop atherosclerotic lesions during the 25 weeks of diet consumption (data not shown).

apoE ${ }^{-/-}$mice also had elevated numbers of $\mathrm{CD} 11 \mathrm{~b}^{+} \mathrm{CD} 90^{+} \mathrm{B} 220^{+}$ CD $49 b^{+} \mathrm{NK} 1.1^{+} \mathrm{Ly}-6 \mathrm{C}^{+}$cells (chow, $3.0 \% \pm 0.1 \%$ cells; Western diet, $3.8 \% \pm 0.4 \%$ cells) than apoE ${ }^{+/+}$mice (chow, $1.8 \% \pm 0.3 \%$ cells; Western diet, $1.9 \% \pm 0.2 \%$ cells). These cells were phenotypically distinct from monocytes and were not examined further.

Although the number of circulating monocytes increased dramatically in apoE ${ }^{-/-}$mice fed Western diet, Ly-6Chi cells consistently expressed CD62 ligand (CD62L; also known as L-selectin) but not CD11c, while Ly-6C $C^{\text {lo }}$ cells consistently expressed low levels of CD11c but not CD62L (Figure 1F), as previously reported for these monocyte subsets (21). Morphologic analysis of flow-sorted cells also showed that cells of both subsets retained their size as well as their characteristic kidney- or horseshoe-shaped nuclei (Figure 1G).

Having determined that numbers of circulating monocytes increased in apoE $\mathrm{E}^{-/-}$mice on Western diet, we assessed the spatial and temporal course of monocytosis development by quantification of monocytes and their subsets in the bone marrow, peripheral blood, and spleen over 250 days of Western diet consumption (Figure 2A). Analysis included additional compartments because the bone marrow produces monocytes and the spleen may serve as a reservoir for monocytes in the periphery. Monocytosis developed progressively in all 3 compartments, and the blood and spleen showed predominant expansion of the Ly-6Chi subset. Statistical analysis matched the data to an exponential growth curve, permitting determination of doubling time for each tissue. The Ly- $6 \mathrm{C}^{\text {hi }}$ subset showed the lowest doubling times ( $95 \%$ confidence interval, 33 to 38 days in the blood), while, as expected, the Ly-6C lo monocyte subset had the highest doubling times ( $95 \%$ confidence interval, 145 to 256 days in the blood). 

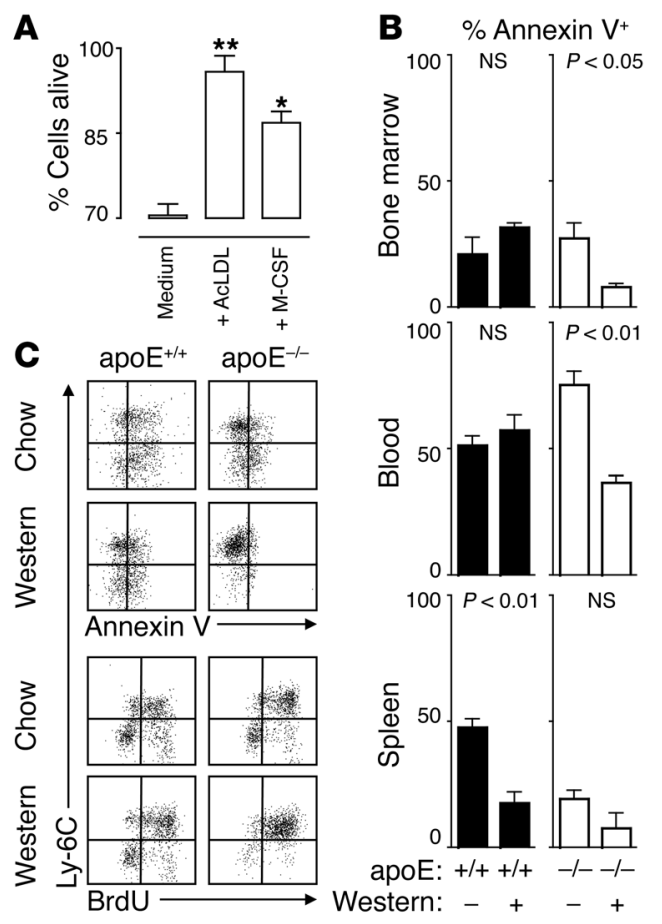
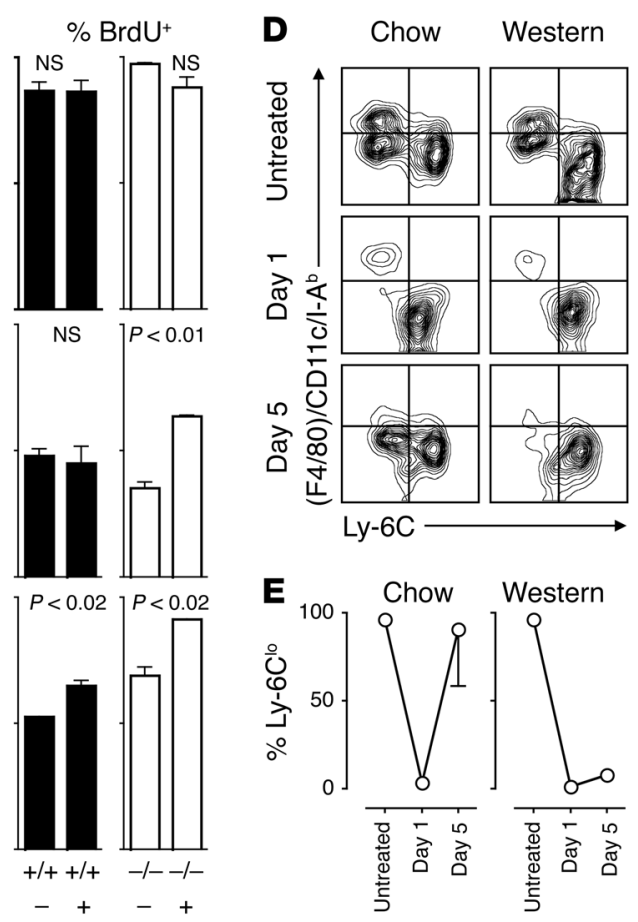

Figure 3

Ly-6Chi monocytosis results from increased survival, continued proliferation, and impaired Ly- $6 \mathrm{C}^{\text {hi }}$ to Ly- $6 \mathrm{C}^{\mathrm{lo}}$ monocyte conversion. (A) Ly-6Chi monocytes from the spleens of apoE $\mathrm{E}^{-/-}$mice were placed into culture with medium alone or medium supplemented with $100 \mu \mathrm{g} / \mathrm{ml} \mathrm{AcLDL} \mathrm{or} 50 \mu \mathrm{g} / \mathrm{ml} \mathrm{M-CSF}$. The percentage of cells alive 24 hours later was calculated based on the ratio of retrieved and input cell numbers. ${ }^{\star \star} P<0.01,{ }^{\star} P<0.05$ versus medium alone (1-way ANOVA with Tukey's multiple comparison test). (B) apoE $\mathrm{E}^{+/+}$and apoE ${ }^{-/-}$mice on chow and Western diet received 3 i.p. injections of BrdU on 3 consecutive days. Cells from bone marrow, blood, and spleen were collected 1 day after the last injection and labeled with annexin $\mathrm{V}$ or anti-BrdU mAb. Results are shown for gated CD11 $\mathrm{b}^{\text {hi }} \mathrm{CD} 90^{\mathrm{lo}} \mathrm{B} 220^{\mathrm{lo}} \mathrm{CD} 49 \mathrm{~b}^{\mathrm{lo}} \mathrm{NK} 1.1^{\mathrm{lo}} \mathrm{Ly}-6 \mathrm{G}^{\mathrm{lo}}$ monocytes as identified in Figure 1. Statistical analyses were performed using Student's $t$ test. (C) Representative dot plots depicting annexin V staining and BrdU incorporation in splenic CD11 b ${ }^{\text {hi }} \mathrm{CD} 90^{\circ} \mathrm{B} 220^{\mathrm{lo}} \mathrm{CD} 49 \mathrm{~b}^{\mathrm{lo}} \mathrm{NK} 1.1^{\mathrm{lo}} \mathrm{Ly}-6 \mathrm{G}^{\mathrm{lo}}$ monocytes from apo $\mathrm{E}^{+/+}$and $a p o \mathrm{E}^{-/-}$mice on chow and Western diet. (D) apoE $\mathrm{E}^{-/-}$mice on chow and Western diet received clodronate liposomes on day 0 . Representative contour plots depict Ly-6C versus F4/80/I-A $/ C D 11 \mathrm{C}$ phenotype among splenic $\mathrm{CD} 11 \mathrm{~b}^{\mathrm{hi}} \mathrm{CD} 90^{\mathrm{lo}} \mathrm{B} 220^{\mathrm{lo}} \mathrm{CD} 49 \mathrm{~b}^{\mathrm{lo}} \mathrm{NK} 1.1^{\mathrm{lo}} \mathrm{Ly}-6 \mathrm{G}^{\mathrm{lo}}$ monocytes on days 1 and 5 or in age-matched untreated mice. (E) Percent of splenic Ly-6Clo monocytes recovered after clodronate liposome injection in apoE ${ }^{-/}$mice on chow and Western diet compared with absolute number of cells in age-matched untreated mice. Shown are 1 of 2-3 independent experiments.

Control experiments used blood from apoE $\mathrm{E}^{+/+}$and apoE $\mathrm{E}^{-/-}$mice during 250 days of chow consumption (Figure $2 \mathrm{~B}$ ). apoE $\mathrm{E}^{+/+}$mice on chow did not develop monocytosis, excluding the possibility that age drives the increase. apoE ${ }^{-/-}$mice on chow showed moderate monocytosis. Statistical analysis matched the data to an exponential growth curve, though doubling times (e.g., $95 \%$ confidence interval, 63 to 86 days for Ly-6Chi monocytes in the blood) were 1.9-2.3 times longer than in $\mathrm{apoE}^{-/-}$mice on Western diet. Thus, atherosclerosis and Ly- $6 \mathrm{C}^{\text {hi }}$ monocytosis arise concomitantly in apoE $\mathrm{E}^{-/-}$mice and show aggravation by Western diet.

Although we used the same criteria to define monocytes in the bone marrow and spleen as in blood (e.g., the CD $11 b^{\text {hi }} \mathrm{CD} 90^{\text {lo }} \mathrm{B}$ $220^{\text {lo }} \mathrm{CD} 49 \mathrm{~b}^{\text {lo }} \mathrm{NK} 1.1^{\text {lo }} \mathrm{Ly}-6 \mathrm{G}^{\mathrm{lo}}$ phenotype), the preponderance of macrophages and dendritic cells in the spleen necessitated a secondary step to ensure that the cells were indeed monocytes. In the spleen, monocytes were further defined as $\mathrm{F} 4 / 80^{\mathrm{lo}} \mathrm{CD} 11 \mathrm{c}^{\mathrm{lo}} \mathrm{I}-\mathrm{A}^{\mathrm{b}}-$ low. These cells had the same morphology as blood monocytes, whereas cells positive for $\mathrm{F} 4 / 80$, I- $\mathrm{A}^{\mathrm{b}}$, and/or CD11c resembled Supplementation of medium with M-CSF $(50 \mu \mathrm{g} / \mathrm{ml})$ for 24 hours partially fostered Ly-6Chi monocyte survival (Figure 3A).

These data suggest that LDL and/or its derivatives directly and indirectly promote the survival of Ly- $6 \mathrm{C}^{\text {hi }}$ monocytes. Nevertheless, the in vitro conditions used may not reproduce the in vivo environment in apo $\mathrm{E}^{-/-}$mice on Western diet, since the number of Ly-6Chi monocytes did not increase in vitro. Therefore, we sought to compare directly the proliferation and survival of monocytes in vivo. apoE-/-animals consuming either chow or Western diet received daily i.p. injections of BrdU for 3 days and were sacrificed 1 day later. Mononuclear cells were purified from the bone marrow, blood, and spleen, and monocytes were analyzed for apoptosis (annexin $\mathrm{V}$ ) and proliferation (anti-BrdU mAb). The Western diet decreased the number of annexin $\mathrm{V}^{+}$cells within Ly-6Chi monocytes in the bone marrow and peripheral blood but not in the spleens of apoE $/$ - mice (Figure 3, B and C). The Western diet concurrently increased the number of $\mathrm{BrdU}^{+}$cells within Ly- $6 \mathrm{Ch}^{\mathrm{hi}}$ monocytes in peripheral blood and the spleen (Figure 3, B and C). 

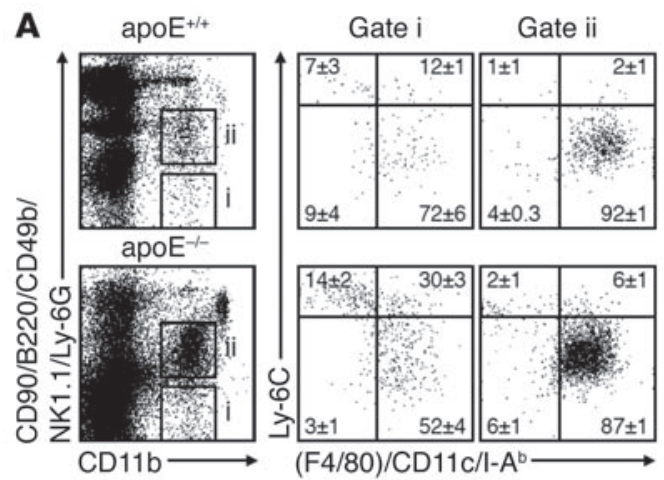

B

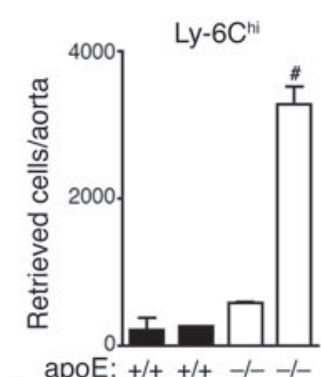
Western: $-++++-1+-$ C
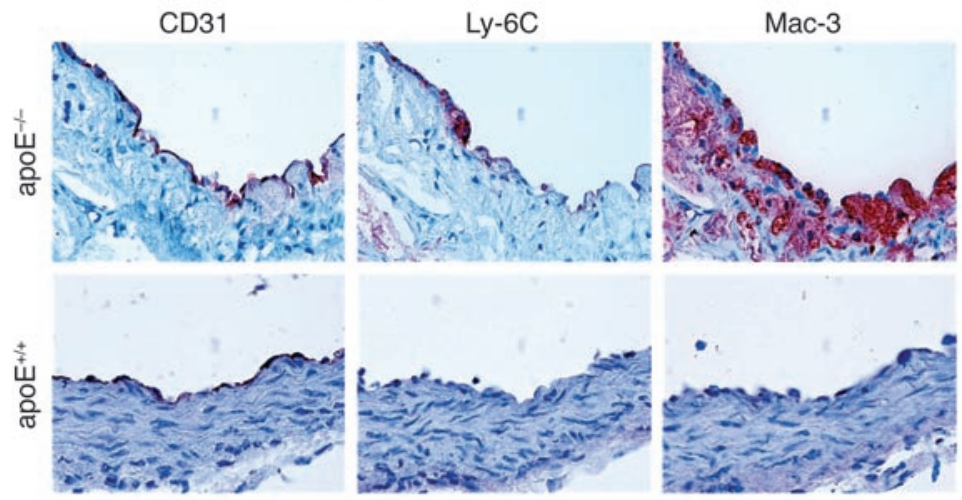

\section{Figure 4}

Atherosclerotic lesions contain Ly-6C hi monocytes. (A) Aortas from apoE $E^{+/+}$ and apoE $\mathrm{E}^{-/-}$mice on chow and Western diet were digested with a protease cocktail. Cells were dispersed and stained with anti-CD11b, -CD90, -B220, -CD49b, -NK1.1, -Ly-6G, -F4/80, $-I-A^{b},-C D 11 c$, and -Ly-6C mAb. Percent (mean \pm SEM) are shown for each quadrant. (B) Number of retrieved Ly-6Chi and Ly-6Clo monocytes per aorta in apoE $\mathrm{E}^{+/+}$and apoE $\mathrm{E}^{-/-}$mice on chow and Western diet. Results are pooled from 5 independent experiments with 2-5 mice per group. Mean and SEM are shown. ${ }^{P}<0.001$ versus all other groups (1-way ANOVA with Tukey's multiple comparison test). (C) Immunohistochemistry depicts the intima at the aortic root of a representative apoE $\mathrm{E}^{-/-}$mouse on Western diet and an apoE $\mathrm{E}^{+/+}$mouse on chow. Sections stained with anti-CD31, -Ly-6C, and -Mac-3 mAbs are shown. Original magnification, $\times 400$.
The vast majority of bone marrow monocytes incorporated BrdU regardless of diet, likely reflecting the continuous medullary production of these cells. These observations reflect the increased survival of dividing Ly- $6 \mathrm{C}^{\text {hi }}$ monocytes in apoE $\mathrm{E}^{-/-}$mice consuming Western diet, but may result from accelerated production in the bone marrow and/or from increased extramedullary proliferation. Interestingly, the higher levels of $\mathrm{BrdU}$ incorporation by Ly-6 $\mathrm{C}^{\text {hi }}$ monocytes in the spleen (mean fluorescence intensity, $528 \pm 111$ ) compared with the bone marrow (mean fluorescence intensity, $293 \pm 63$ ) indicate either continued proliferation in the periphery or selective emigration from the bone marrow of cells with longer proliferative histories.

Analysis of apoptosis and proliferation in apoE $\mathrm{E}^{+/+}$mice showed that Western diet increased survival and proliferation of monocytes in the spleen but not in the bone marrow or blood (Figure 3, B and C). Because apoE regulates apoptosis and cell cycle $(28,29)$, it may participate in the differences observed between $\mathrm{apoE}^{+/+}$and $\mathrm{apoE}^{-/-}$mice.

To determine whether the Western diet also affects conversion of Ly- $6 \mathrm{C}^{\text {hi }}$ to Ly- $6 \mathrm{C}^{\text {lo }}$ monocytes, apoE $\mathrm{E}^{-/-}$mice on chow and Western diet received clodronate liposomes to deplete endogenous circulating monocytes (24). Mice administered clodronate liposomes had a dramatically reduced number of Ly- $6 \mathrm{C}^{\mathrm{lo}} \mathrm{F} 4 / 80^{\mathrm{lo}} \mathrm{CD} 11 \mathrm{c}^{\mathrm{lo}} \mathrm{I}-\mathrm{A}^{\mathrm{b}}-\mathrm{low}$ monocytes in blood (chow, $0.6 \pm 0.2 \times 10^{4}$ versus $8.7 \pm 4.6 \times 10^{4}$ cells $/ \mathrm{ml}$; Western diet, $1.1 \pm 0.6 \times 10^{4}$ versus $9.6 \pm 1.3 \times 10^{4}$ cells $/ \mathrm{ml}$ ) and spleen (chow, $2.4 \pm 1.1 \times 10^{4}$ versus $32.5 \pm 7.3 \times 10^{4}$ cells $/ \mathrm{ml}$; Western diet, $3.8 \pm 0.9 \times 10^{4}$ versus $381.0 \pm 84.2 \times 10^{4}$ cells $/ \mathrm{ml}$ ) 1 day after injection. Clodronate also strongly reduced the number of

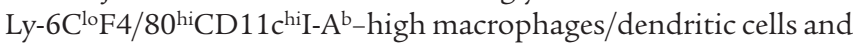
moderately reduced the number of Ly- $6 \mathrm{C}^{\mathrm{hi}} \mathrm{F} 4 / 80^{\mathrm{lo}} \mathrm{CD} 11 \mathrm{c}^{\mathrm{lo}} \mathrm{I}-\mathrm{A}^{\mathrm{b}}-$ low monocytes (Figure 3D and data not shown). The near absence of Ly-6Clo monocytes on day 1 allowed us to study their reemer- gence from the Ly-6Chi repertoire (Figure 3, D and E). Five days after clodronate injection, Ly- $6 \mathrm{C}^{\mathrm{lo}}$ monocytes had repopulated both blood and spleen in animals on chow but not in animals consuming Western diet (Figure 3, D and E, and data not shown). Impaired Ly-6 $\mathrm{C}^{\text {hi }}$ to Ly- $6 \mathrm{C}^{\text {lo }}$ conversion in apoE $\mathrm{E}^{-/-}$mice consuming Western diet fostered Ly-6Chi monocytosis.

Ly-6C ${ }^{b i}$ monocytes accumulate selectively in atherosclerotic lesions. Adoptively transferred $\mathrm{EGFP}^{+}$monocytes accumulate in atherosclerotic lesions (16), but low numbers of $\mathrm{EGFP}^{+}$signals detected by immunohistochemistry prevent quantification of cell accumulation. Here we employed a recently established flow cytometry method (30) to phenotype single-cell suspensions of enzymedigested aortas and determined the in vivo relevance of Ly- $6 \mathrm{Ch}^{\mathrm{hi}}$ monocytosis to atherosclerosis. Aortas from apoE $\mathrm{p}^{+/+}$and $\mathrm{apoE}^{-/-}$ animals on either chow or Western diet contained at least 2 distinct populations of cells expressing CD11b, identified in gate $i$ as putative monocytes and in gate ii as putative macrophages (Figure $4, \mathrm{~A}$ and B). Cells detected in gate i fell into 4 phenotypically distinct populations: $\mathrm{Ly}-6 \mathrm{C}^{\mathrm{hi}} \mathrm{F} 4 / 80^{\mathrm{lo}} \mathrm{CD} 11 \mathrm{c}^{\mathrm{lo}} \mathrm{I}-\mathrm{A}^{\mathrm{b}}-\mathrm{low}$, Ly-6ChiF4 $/ 80^{+}$CD $11 c^{+} I-A^{b}$-positive, Ly-6C ${ }^{\text {int } F 4 / 80^{+}}$CD $11 c^{+} I-A^{b}-$ positive, and $\mathrm{Ly}-6 \mathrm{C}^{\mathrm{lo}} \mathrm{F} 4 / 80^{\mathrm{lo}} \mathrm{CD} 11 \mathrm{c}^{\mathrm{lo}} \mathrm{I}-\mathrm{A}^{\mathrm{b}}-\mathrm{low}$, resembling circulating Ly-6Chi monocytes, monocytes in the process of differentiation, differentiated macrophages and/or dendritic cells, and Ly-6C ${ }^{\text {lo }}$ monocytes, respectively (Figure 4A).

Enumeration showed 3,280 \pm 240 Ly-6ChiF4/80 ${ }^{\text {lo }} \mathrm{CD} 11 \mathrm{c}^{\mathrm{lo}} \mathrm{I}-\mathrm{A}^{\mathrm{b}}-$ low monocytes in the aortas of apoE $\mathrm{E}^{-/-}$mice on Western diet, but only $580 \pm 20$ in the aortas of $\mathrm{apoE}^{-/-}$mice on chow. By comparison, aortas showed few Ly- $6 \mathrm{C}^{\mathrm{lo}} \mathrm{F} 4 / 80^{\text {lo }} \mathrm{CD} 11 \mathrm{c}^{\mathrm{lo}} \mathrm{I}-\mathrm{A}^{\mathrm{b}}-\mathrm{low}$ monocytes $\left(580 \pm 70\right.$ and $500 \pm 90$ cells in $\mathrm{apoE}^{-/-}$mice on Western diet and chow, respectively; Figure 4B). Thus Western diet selectively increased Ly-6 $\mathrm{C}^{\text {hi }}$ monocyte accumulation in atherosclerotic aortas of apoE $\mathrm{E}^{-/}$mice. As expected, aortas contained more macrophages 
A
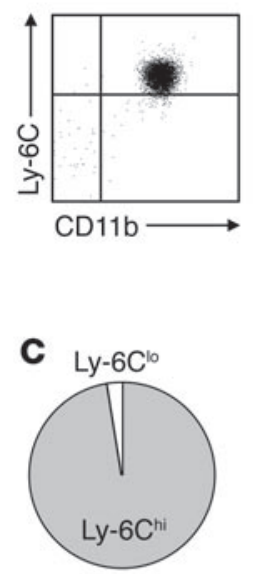

E

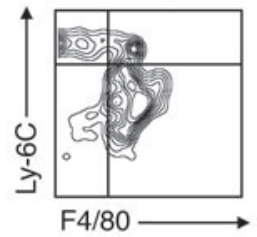

B

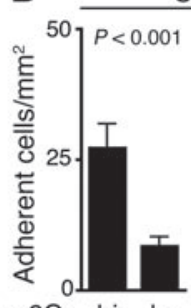

Ly-6C: hi lo

apoE: $+/++/+$
Chow

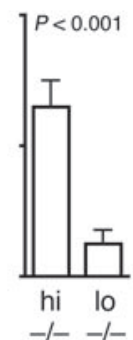

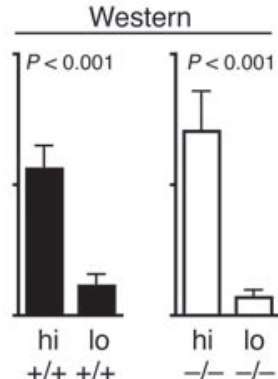

D
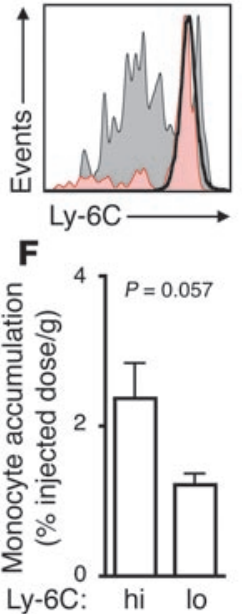

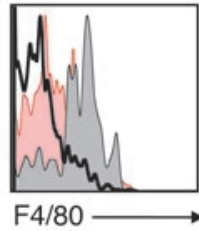

G

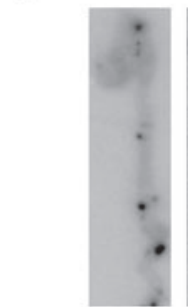

Ly-6C:

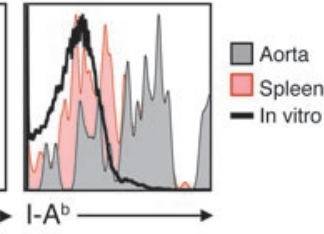

H
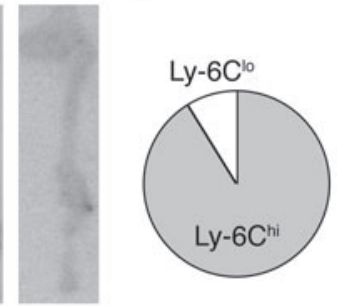

lo

\section{Figure 5}

Ly- $6 \mathrm{C}^{\text {hi }}$ monocytes adhere preferentially to TNF- $\alpha$-activated endothelium, accumulate in lesions, and differentiate to macrophages in vivo. (A) Purified Ly- $6 \mathrm{C}^{\text {hi }}$ monocyte phenotype after 24 hours in culture. (B) Adherence of blood monocytes on TNF- $\alpha-$ treated MHECs under laminar flow conditions. Monocyte subsets were isolated from the blood of apoE $\mathrm{E}^{+/+}$and apoE $\mathrm{E}^{-/-}$mice on chow and Western diet. (C) Relative proportion of blood monocytes expected to adhere to activated endothelium, based on the capacity of each subset to adhere and their average abundance in peripheral blood of apo $E^{-/}$mice on Western diet for 25 weeks. (D) Ly-6C, F4/80, and I-A $\mathrm{A}^{\mathrm{b}}$ expression of CD45.2+ Ly-6C hi monocytes retrieved from aortas and spleens 24 hours after transfer into CD45.1+ mice (both donor and recipient apoE-/- mice consuming a Western diet). Monocytes cultured in vitro were also analyzed. (E) F4/80 and Ly-6C coexpression on $\mathrm{CD} 45.2^{+}$donor cells retrieved from aortas. (F) In vivo aortic accumulation of [111In]oxine-labeled Ly-6C ${ }^{\text {hi }}$ and Ly-6C ${ }^{\text {lo }}$ monocytes 24 hours after adoptive transfer in apoE $\mathrm{E}^{-/-}$mice on Western diet. (G) Phosphorimager plates depicting relative distribution of signal in aortas of apoE ${ }^{-/-}$mice that received equal numbers of $\mathrm{Ly}-6 \mathrm{C}^{\text {hi }}$ apoE $\mathrm{E}^{-/-}$or Ly-6Clo apoE $\mathrm{C}^{-/-}$monocytes. (H) Relative proportion of Ly-6Chi and Ly-6Clo monocytes expected to accumulate in atherosclerotic aortas, based on the capacity of each subset for aortic accumulation and their average abundance in peripheral blood of apoE $\mathrm{E}^{-/-}$mice on Western diet for 25 weeks. Shown are 1 of 2-3 independent experiments. Student's $t$ test was used.

and/or dendritic cells in apoE $\mathrm{E}^{-/-}$mice on Western diet (gate ii; $4.9 \pm 1.7 \times 10^{4}$ cells $)$ than on chow $\left(1.1 \pm 0.3 \times 10^{4}\right.$ cells $)$.

We counted relatively low numbers of $\mathrm{Ly}-6 \mathrm{C}^{\text {hi }}$ and $\mathrm{Ly}-6 \mathrm{C}^{\mathrm{lo}}$ monocytes and macrophages/dendritic cells in the aortas of apoE $\mathrm{E}^{+/+}$ mice regardless of diet (Western diet, $260 \pm 10$ Ly-6Chi monocytes, $310 \pm 160$ Ly-6Clo monocytes, $1.3 \pm 0.5 \times 10^{4}$ macrophages/dendritic cells; chow, $220 \pm 170$ Ly- $6 C^{\text {hi }}$ monocytes, $230 \pm 120$ Ly- $6 C^{\text {lo }}$ monocytes, $1.2 \pm 0.3 \times 10^{4}$ macrophages/dendritic cells; Figure 4B).

The above cell numbers likely underestimate actual values, since the enzymatic digestion of aortic tissue required to obtain singlecell suspensions caused the death of many cells $(90 \% \pm 1 \%$ of events

contributed to debris and dead cells, as defined by low forward scatter) that were excluded from the analysis. The actual difference in Ly-6 $\mathrm{Ch}^{\text {hi }}$ and Ly-6C $\mathrm{C}^{\mathrm{lo}}$ monocyte numbers is overestimated if Ly-6Clo monocytes are more likely to die during isolation.

We performed immunohistochemical examination of aortic roots isolated from the apoE $\mathrm{E}^{-/-}$mice described above to evaluate the spatial distribution of Ly-6Chi cells in severe (fibrous plaque) and early (fatty streak) lesions (Figure 4C and data not shown). Ly-6C colocalized with mononuclear-like cells on the intimal face of $\mathrm{CD} 31^{+}$endothelial cells but not with the bulk of Mac- $3^{+}$macrophage-rich areas in both types of lesions. These observations suggest that Ly-6Chi monocytes migrate to early and severe lesions and that differentiation into macrophages accompanies transmigration into the artery, although some Ly- $6 \mathrm{C}^{\text {hi }}$ monocytes may reside in the innermost layer of the intima. The relative number of Ly-6Chi cells compared with the number of Mac- $3^{+}$cells in these regions was 4.8 times higher in severe than in early lesions, suggesting that $\mathrm{Ly}-6 \mathrm{C}^{\text {hi }}$ monocytes migrate more efficiently to severe lesions.

Ly-6C $C^{\text {hi }}$ monocytes adhere preferentially to activated endothelium, accumulate in atherosclerotic plaques, and rapidly become lesional macrophages. Further examination followed the activity and fate of Ly-6Chi and Ly- $6 \mathrm{C}^{\text {lo }}$ monocytes isolated from either $\mathrm{apoE}^{-/-}$or apoE ${ }^{+/+}$mice on Western diet or chow. More than $70 \%$ of the cells remained alive in culture 24 hours after the isolation procedure (data not shown) and preserved monocytic markers (i.e., Ly-6Chi or Ly-6Clo,

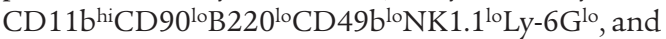
$\mathrm{F} 4 / 80^{\mathrm{lo}} \mathrm{CD} 11 \mathrm{c}^{\mathrm{lo}} \mathrm{I}-\mathrm{A}^{\mathrm{b}}$-low; Figure $\left.5 \mathrm{~A}\right)$. We initially determined the capacity of monocyte subsets to adhere to TNF- $\alpha$-activated murine cardiac endothelium under laminar flow conditions. Freshly isolated blood Ly-6C ${ }^{\text {hi }}$ monocytes from apoE-/- mice on either Western diet or chow adhered efficiently to the endothelium within minutes, while Ly-6C ${ }^{\text {lo }}$ cells adhered significantly less well (Figure 5B, white bars), as did naive lymphocytes (data not shown). Similar results were observed with monocytes isolated from apoE ${ }^{+/+}$mice (Figure 5B, black bars). These results indicate that Ly- $6 \mathrm{C}^{\text {hi }}$ monocytes adhere preferentially to activated endothelium independent of diet or of the presence or absence of apoE. The relative proportion of circulating Ly- $6 \mathrm{C}^{\mathrm{hi}}$ and Ly-6C $\mathrm{C}^{\text {lo }}$ monocyte subsets in apoE-/- mice on Western diet suggests that greater than $95 \%$ of cells capable of binding to activated endothelium would belong to the Ly-6C $\mathrm{C}^{\text {i }}$ subset (Figure $5 \mathrm{C}$ ).

Further exploration used adoptive transfer of Ly- $6 \mathrm{C}^{\text {hi }}$ monocytes from CD45.2 apoE $\mathrm{ap}^{-/-}$mice into congenic CD45.1 apoE $\mathrm{ap}^{-/-}$recipients (both donor and recipient mice on Western diet for 25 weeks). Because peripheral blood contains few monocytes, splenic monocytes served as surrogates for circulating monocytes. After 24 hours, aortas from recipient mice were digested enzymatically, and single-cell suspensions were analyzed by flow cytometry. We counted $135 \pm 4$ donor cells in recipient aortas, of which approxi- 
A

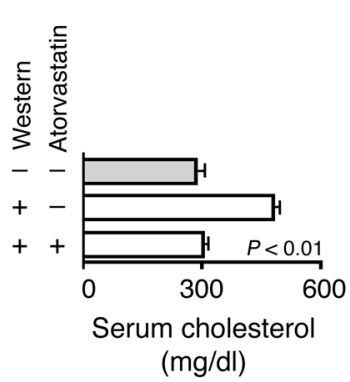

B
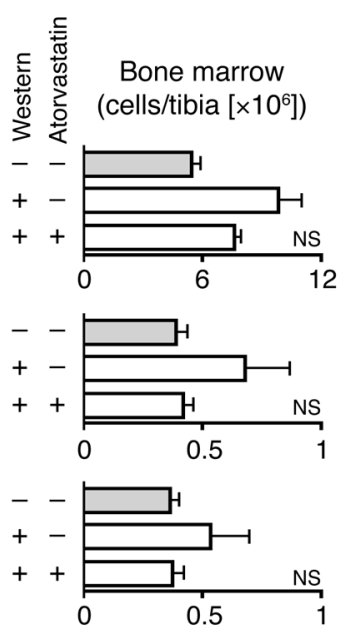

$--p$

$++7$

$\begin{array}{lll} & & \text { NS } \\ 0 & 0.5 & 1\end{array}$
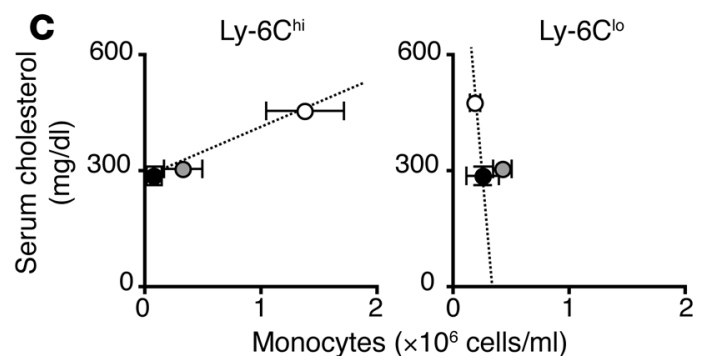

(cells/spleen $\left[\times 10^{6}\right]$ )
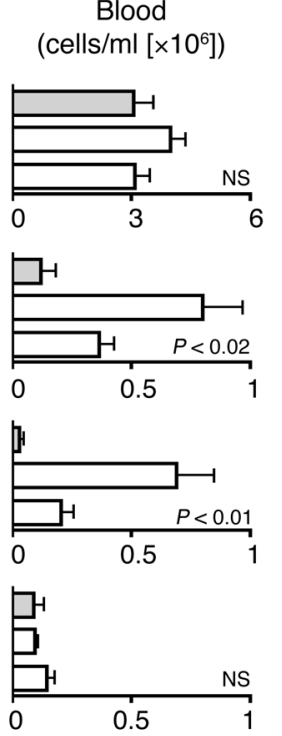
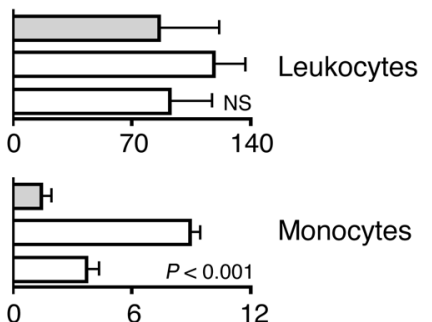

t
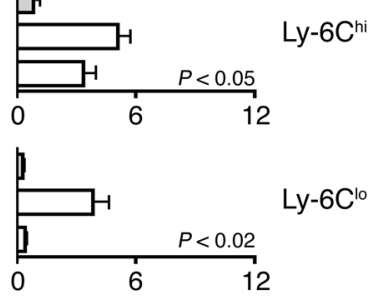

\section{Figure 6}

Statin treatment limits monocytosis. apoE ${ }^{-/-}$ mice consumed Western diet supplemented or not with atorvastatin for 25 weeks. A control group of apoE $\mathrm{E}^{-/-}$mice received regular chow. (A) Serum cholesterol after 25 weeks of diet. (B) Number of leukocytes, monocytes, and $L y-6 C^{\text {hi }}$ and $L y-6 C^{l o}$ subtypes in bone marrow, blood, and spleen. (C) Association between serum cholesterol and number of circulating Ly-6Chi or Ly-6Clo monocytes after 25 weeks of diet. Mean \pm SEM are shown for apoE-/- mice on chow (filled circles), Western diet (open circles), and Western diet supplemented with atorvastatin (gray circles). Results are pooled from 9 independent experiments $(n=3-14$ per group). Student's $t$ test was used. mately $25 \%$ were Ly- $6 \mathrm{C}^{\text {hi }}$ and approximately $75 \%$ were $\mathrm{Ly}-6 \mathrm{C}^{\mathrm{lo}}$ (Figure 5D). Many donor cells showed enhanced expression of F4/80 and I-A ${ }^{\mathrm{b}}$ (Figure 5D). Remarkably, the combined analysis of Ly-6C and F4/80 expression by donor cells revealed the existence of at least 3 distinct populations, Ly- $6 \mathrm{C}^{\text {hi }} \mathrm{F} 4 / 80^{-}$, Ly- $6 \mathrm{C}^{\mathrm{hi}} \mathrm{F} 4 / 80^{+}$, and $\mathrm{Ly}-6 \mathrm{C}^{\mathrm{lo}} \mathrm{F} 4 / 80^{+}$, resembling monocytes, monocytes in the process of differentiating into macrophages, and mature macrophages, respectively (Figure 5E). These phenotypic relationships are comparable to those observed among endogenous populations (Figure 4A). In contrast, donor cells retrieved from the spleens of the same mice remained phenotypically unchanged (Figure 5D). These results demonstrate recruitment of Ly- $6 \mathrm{C}^{\text {hi }}$ monocytes to atherosclerotic aortas, followed by local and rapid ( $<24$ hours) differentiation into macrophages. Combined with the restricted localization of Ly-6Chi monocytes to the luminal face of the endothelium, these data suggest that differentiation into macrophages accompanies transmigration and also support the notion that aortic monocyte detection did not result from contamination of circulating cells.

To determine the relative capacity of Ly- $6 \mathrm{C}^{\text {hi }}$ and Ly- $6 \mathrm{C}^{\text {lo }}$ monocytes to migrate to atherosclerotic aortas and to determine whether accumulation of Ly-6Chi cells mapped to lesions, we labeled equal numbers of splenic Ly-6Chi and Ly-6Clo monocytes from apoE $\mathrm{E}^{-/-}$mice on Western diet with [ $\left.{ }^{111} \mathrm{In}\right]$ oxine and injected them separately into apoE $\mathrm{E}^{-/}$mice on Western diet. After 24 hours, we excised the aortas and calculated the percent injected dose per gram of tissue, which revealed that Ly- $6 \mathrm{C}^{\text {hi }}$ cells preferentially accumulated in aortas (Figure 5F). Autoradiography showed discrete regions of activity only in recipients of Ly-6Chi cells (Figure 5G). The lack of such regions in animals receiving Ly- $6 C^{\text {lo }}$ cells suggests that the signals detected in these mice corresponded to background activity. The radioactive signal observed for Ly-6Chi cells always mapped directly to areas containing lesions as determined microscopically, but not all lesions showed focal areas of radioactivity (data not shown). The relative proportion of circulating Ly- $6 \mathrm{C}^{\text {hi }}$ and Ly- $6 \mathrm{C}^{\text {lo }}$ monocyte subsets in apoE $\mathrm{E}^{-/-}$mice on Western diet suggests that greater than $90 \%$ of cells accumulating in atherosclerotic lesions originate from the Ly-6Chi subset (Figure $5 \mathrm{H}$ ). Taken together, these results suggest that circulating Ly-6Chi monocytes are direct precursors of lesional macrophages.

Expression of MCP-1 by a subset of cells in atherosclerotic lesions suggests active recruitment of monocytes to developing lesions in vivo $(31,32)$, and mice lacking MCP-1 or C-C motif chemokine receptor 2 (CCR2) show reduced atherosclerosis (33-35). Thus monocyte recruitment into lesions may require CCR2 expression, a feature of the Ly- $6 C^{\text {hi }}$ subtype (19). Testing this hypothesis involved the adoptive transfer of Ly- $6 \mathrm{C}^{\text {hi }}$ monocytes from bone marrow of CCR2 $2^{-/-}$mice into peripheral blood of atherosclerotic $\left(\mathrm{CCR}^{+/+}\right) \mathrm{apoE}^{-/-}$mice. We counted only $14 \pm 2$ donor cells in recipient aortas, suggesting that $\mathrm{Ly}-6 \mathrm{C}^{\text {hi }}$ monocyte accumulation in lesions does indeed depend on CCR2.

Statin administration attenuates $L y-6 C^{\text {hi }}$ monocytosis. Having shown that lesional macrophages were derived from circulating $\mathrm{Ly}-6 \mathrm{C}^{\mathrm{hi}}$ monocytes in atherosclerosis, we sought to determine whether 
reduction of Ly- $6 \mathrm{C}^{\text {hi }}$ monocytosis attenuates disease. Repeated administration of anti-Ly- $6 \mathrm{C}$ mAb could theoretically control Ly-6Chi monocytosis. This approach is impractical, given the chronic nature of atherogenesis, and may not keep the size of the Ly-6Chi monocyte population at homeostatic levels, but rather trigger transient cell depletion upon each mAb injection. In contrast, since inhibitors of hydroxymethylglutaryl coenzyme A reductase (statins) decrease cholesterol levels, exert antiinflammatory effects, and attenuate atherosclerosis $(36,37)$, we sought to determine whether concurrent treatment of apoE-/- mice on Western diet with statin also modulates the extent of monocytosis. Mice analyzed after 25 weeks of atorvastatin treatment had significantly attenuated serum cholesterol levels when compared with age-matched littermates on Western diet (Figure 6A). The statin treatment also reduced monocytosis (Figure 6B). Specifically, the numbers of Ly- $6 \mathrm{C}^{\text {hi }}$ monocytes declined significantly in the spleen and peripheral blood (although they remained higher than in apoE $/ /-$ mice on chow), whereas the numbers of Ly-6Chi monocytes in the bone marrow fell to levels found in apoE $\mathrm{E}^{-/-}$mice on chow (Figure 6B). The statin treatment also reduced the numbers of the Ly- $6 \mathrm{C}^{\text {lo }}$ monocytes in the spleen. Antiinflammatory effects of statins beyond LDL lowering could also participate in the attenuation of Ly- $6 \mathrm{C}^{\text {hi }}$ cell numbers.

Blood Ly-6Chi monocyte counts positively associated with serum cholesterol levels in apoE $\mathrm{E}^{+/+}$(data not shown) and $\mathrm{apoE}^{-/-}$ mice (Figure 6C). Furthermore, correlation between Ly-6Chi numbers from statin-treated apo $\mathrm{E}^{-/-}$mice conformed to a linear axis between chow- and Western diet-fed animals. Such correlative analysis did not apply for blood Ly-6 $\mathrm{C}^{\text {lo }}$ monocytes, since Ly-6Clo cell counts were similar for all serum cholesterol concentrations.

\section{Discussion}

This study shows that hypercholesterolemia in apoE ${ }^{-/-}$mice induced the progressive and selective expansion of Ly- $6 \mathrm{C}^{\mathrm{hi}}$ monocytes, a phenomenon we have termed HAM. Ly-6Chi monocytes participate in atherosclerosis because they preferentially adhered to activated endothelium, accumulated in lesions, and locally differentiated into macrophages, the predominant leukocytes during plaque inflammation and development. Although we did not describe a role for $\mathrm{Ly}-6 \mathrm{C}^{\mathrm{lo}}$ cells in atherosclerosis, future studies may determine whether this subset, as a possible precursor of dendritic cells (38), influences the adaptive arm of the immune system, particularly with respect to antigen presentation and lymphocyte activation, processes known to occur in atherosclerosis (1).

HAM results from continued bone marrow production of $\mathrm{Ly}-6 \mathrm{C}^{\mathrm{hi}}$ monocytes, increased survival of these cells in the periphery, and impaired conversion to the Ly- $6 \mathrm{C}^{\mathrm{lo}}$ subset. Monocytosis was characterized by a doubling of the $\mathrm{Ly}-6 \mathrm{C}^{\text {hi }}$ population every month in peripheral blood, generating up to $1.4 \times 10^{6}$ cells/ml after 250 days of diet; although the rate of Ly- $6 \mathrm{C}^{\text {hi }}$ monocytosis was slightly slower in the spleen (doubling time of around 2 months), this organ served as a much larger reservoir of Ly-6 $\mathrm{Ch}^{\text {hi }}$ monocytes, reaching approximately $2 \times 10^{7}$ cells after 250 days of diet. Moreover, since the number of Ly-6Chi monocytes continuously increased during the 250 days of the study, monocyte expansion would likely have persisted beyond this point.

We suggest that Ly-6Chi monocytosis requires elevated concentrations of cholesterol or lipid derivatives, since (a) monocytosis occurred in mice fed Western diet, (b) the presence of a choles- terol-lowering drug of the statin class at least partially controlled monocytosis in vivo, and (c) the addition of LDL for 24 hours to purified Ly-6Chi monocytes in vitro allowed for their increased survival without promoting differentiation into macrophages. These findings demonstrate that augmented serum cholesterol levels, in addition to promoting lipid deposition in lesions (39) and inducing M-CSF production for local monocyte maturation into macrophages $(40,41)$, also trigger the expansion of circulating monocytes. These data suggest that a cholesterol-rich diet promotes murine atherogenesis, at least in part through the development of monocytosis. Molecules such as M-CSF, GM-CSF, PI3K, and NF- $\mathrm{KB}$ are induced by constituents of modified LDL and mediate the expansion and maturation of macrophages $(42,43)$. It will be of interest to determine whether similar pathways also elicit Ly-6Chi monocytosis and why circulating Ly- $6 C^{\text {lo }}$ monocytes appear less sensitive to the same stimuli.

Following the fate of adoptively transferred, purified monocyte subsets revealed that lesional macrophages derived predominantly from circulating $\mathrm{Ly}-6 \mathrm{C}^{\mathrm{hi}}$ monocytes, pointing to an active role in this process for the membrane-bound, glycosylphosphatidylinositol-linked protein Ly-6C (44-46). Future studies will show whether Ly-6C serves only as a marker for or also contributes functionally to inflammatory monocytes, whether Ly-6C characterizes inflammatory cells capable of tissue transmigration, and whether therapeutic targeting of Ly-6C, or a human equivalent, contains monocytosis and consequently reduces atherosclerosis.

The observation that Ly- $6 \mathrm{C}^{\text {hi }}$ cells trafficked differentially to lesions supports the concept of heterogeneity of atheromata (47, 48) and suggests that these cells migrate preferentially to lesions of high inflammatory activity. Interestingly, fatty streaks harbored few Ly- $6 C^{\text {hi }}$ monocytes, indicating low monocyte accumulation at this stage. Expression of CD62L also suggests a role for Ly-6Chi monocytes in antigen presentation in secondary lymphoid organs and participation in adaptive immunity.

Activated macrophages, operationally categorized as M1 cells (classically activated macrophages), are induced by IFN- $\gamma$ and generate inflammation, while M2 cells (alternatively activated macrophages) generated in response to IL-4 or IL-13 can exhibit immunoregulatory function $(49,50)$. Ly- $6 \mathrm{C}^{\text {hi }}$ monocytes selectively populate sites of experimentally induced inflammation and can locally differentiate into M1 cells. However, whether the cytokine milieu recruits and/or activates specific monocyte subsets, or indiscriminately polarizes already accumulated subsets for particular macrophage function will require further study.

Clinical data have shown a positive correlation between white blood cell count and acute myocardial infarction (5-7). More recently, a study showed that monocytosis is an independent risk factor for coronary artery disease (51). Here we propose that monocytosis is an etiologic constituent of experimental atherogenesis. Future research will determine whether humans with elevated serum cholesterol and/or C-reactive protein exhibit CD14 ${ }^{\text {hi }} \mathrm{CD} 16^{-}$ monocytosis, and whether this variable relates to atheroma burden or complications. Overall, our present results indicate a striking and dynamic alteration of the monocyte repertoire during experimental atherogenesis, recognize circulating Ly- $6 \mathrm{C}^{\text {hi }}$ monocytes as key mediators of chronic inflammation, and suggest what we believe to be novel mechanistic hypotheses regarding the interface of innate immunity and atherosclerosis that will require future testing experimentally and in humans. 


\section{Methods}

Animals. apoE $\mathrm{E}^{+/+}(\mathrm{C} 57 \mathrm{BL} / 6)$ and apoE $\mathrm{E}^{-/-}$(B6.129P2-Apoe $\left.\mathrm{tm}^{\mathrm{tm} 1 \mathrm{Unc}}\right)$ mice were purchased from The Jackson Laboratory. The apoE- $-1-$ animals had been backcrossed to the $\mathrm{C} 57 \mathrm{BL} / 6$ background for at least 10 generations. apoE ${ }^{-/-} \mathrm{CD} 45.1^{+/+}$mice were generated after backcrossing apoE ${ }^{-/-}$mice to $\mathrm{C} 57 \mathrm{BL} / 6 \mathrm{CD} 45.1^{+/+}$mice (The Jackson Laboratory). C57BL/6 CCR2 ${ }^{-/}$ mice were a gift from B. Rollins (Dana-Farber Cancer Institute, Boston, Massachusetts, USA), A. Luster (Massachusetts General Hospital and Harvard Medical School), and I. Charo (UCSF, San Francisco, California, USA). At 10 weeks of age, groups of animals were placed on a Western diet (21.2\% fat/weight, $0.2 \%$ cholesterol; Harlan Teklad), which was defined as day 0 in this study. The remaining animals consumed a regular chow diet. A group of animals received supplemental atorvastatin in their diet (52) $(0.01 \% \mathrm{w} / \mathrm{w})$ starting on day 0 . All studies were conducted with agematched animals after 20-25 weeks of diet unless otherwise stated. All protocols were approved by the Subcommittee on Animal Research Care (SARC) at Massachusetts General Hospital.

Cells. Cells were harvested from bone marrow, peripheral blood, spleens, and aortas at the time points indicated in Results. Bone marrow from both tibias was harvested, and the cells were collected by inserting a needle into the bone and washing with HBSS supplemented with $0.2 \%$ $(\mathrm{w} / \mathrm{v}) \mathrm{BSA}$ and $1 \%(\mathrm{w} / \mathrm{v})$ FCS. Peripheral blood was drawn via cardiac puncture with citrate solution $(100 \mathrm{mM} \mathrm{Na}$-citrate, $130 \mathrm{mM}$ glucose, $\mathrm{pH}$ 6.5) as anticoagulant, and mononuclear cells were purified by density centrifugation (16). Total leukocyte numbers were determined using acetic acid lysis solution ( $3 \%$ HEMA 3 solution II, 94\% dd $\mathrm{d}_{2} \mathrm{O}, 3 \%$ glacial acetic acid). Blood smears were prepared to corroborate monocyte numbers and subtract percent granulocytes from total leukocyte counts. Spleens were removed, triturated in HBSS (cellgro; Mediatech Inc.) at $4^{\circ} \mathrm{C}$ with the end of a 3-ml syringe, and filtered through nylon mesh (BD Biosciences). Aortas were excised and placed into a cocktail of collagenase I, collagenase XI, DNase I, and hyaluronidase (Sigma-Aldrich) at $37^{\circ} \mathrm{C}$ for 1 hour, as described previously (30). Cells were then triturated through nylon mesh. The cell suspensions were centrifuged ( 15 minutes, $500 \mathrm{~g}, 4^{\circ} \mathrm{C}$ ), red blood cells were lysed with ACK lysis buffer, and the resulting single-cell suspensions were washed with HBSS supplemented with $0.2 \%(\mathrm{w} / \mathrm{v})$ BSA and $1 \%(\mathrm{w} / \mathrm{v})$ FCS.

$m A$ s and flow cytometry. For visualization of monocytes, cells were incubated with a cocktail of mAbs against T cells (CD90-PE, 53-2.1), B cells (B220-PE, RA3-6B2), NK cells (CD49b-PE, DX5 and NK1.1-PE, PK136), granulocytes (Ly-6G-PE, 1A8), myeloid cells (CD11b-APC, M1/70) and monocyte subsets (Ly-6C-FITC, AL-21). In Figure 1F, labeling with Ly-6C-biotin-strep-PerCP was performed so as to allow combination with CD11c-FITC (HL3) and CD62L-FITC (MEL-14). CD45.2-FITC and CD45.2-APC (A20) mAbs were also used (all from BD Biosciences). Monocytes were identified as $\mathrm{CD} 11 \mathrm{~b}^{\text {hi }} \mathrm{CD} 90^{\mathrm{lo}} \mathrm{B} 220^{\mathrm{lo}} \mathrm{CD} 49 \mathrm{~b}^{\mathrm{lo}} \mathrm{NK} 1.1^{\mathrm{lo}} \mathrm{Ly}-6 \mathrm{G}^{\mathrm{lo}}$ cells. F4/80 (BM8)-biotin-strep-PerCP, I-A ${ }^{\text {b }}$ (AF6-120.1)-biotin-strepPerCP and CD11c (HL3)-biotin-strep-PerCP mAbs also served to determine macrophage and dendritic cell differentiation. Monocyte numbers were calculated as total leukocytes (corrected for granulocyte content, as determined on blood smears) multiplied by percent cells within the monocyte gate of the mononuclear cell fraction. Within this population, subsets were identified as either Ly-6Chi or Ly-6 $\mathrm{C}^{\mathrm{lo}}$. The number of cells in each subset was calculated by multiplying monocyte number by percent of cells in the subset. For proliferation studies, mice received $1 \mathrm{mg}$ BrdU i.p. on 3 consecutive days prior to sacrifice on day 4. Cells were stained with antiBrdU or annexin V, according to the manufacturer's protocol (BD Biosciences), and analyzed on a FACSCalibur or flow sorted on a FACSAria (all from BD Biosciences). For depletion of monocytes (24), mice were injected i.v. with $0.2 \mathrm{ml}$ of dichloromethylene-bisphosphonate (clodronate)
(Sigma-Aldrich) liposomes. Clodronate was incorporated into liposomes, as previously described (53). For in vitro studies, cells were placed in complete medium (RPMI 1640 with $1 \mathrm{mM}$ sodium pyruvate, $10 \mathrm{mM}$ HEPES, 2 mM glutamine, $1 \%[\mathrm{w} / \mathrm{v}]$ penicillin/streptomycin and $10 \%[\mathrm{v} / \mathrm{v}]$ FCS previously heat inactivated for 1 hour at $56^{\circ} \mathrm{C}$ ) alone or supplemented with either $100 \mu \mathrm{g} / \mathrm{ml} \mathrm{AcLDL}$ or $50 \mu \mathrm{g} / \mathrm{ml} \mathrm{M-CSF}$ (R\&D Systems). For morphologic characterizations, sorted cells were spun, resuspended in PBS, prepared on slides by cytocentrifugation (Shandon; Thermo Electron Corp.) at $10 \mathrm{~g}$ for 2 minutes, and stained with HEMA-3 (Biochemical Sciences Inc.). Monocytes were identified as cells 10-30 $\mu \mathrm{m}$ in diameter with a horseshoe- or kidney-shaped nucleus, a variable nucleus-to-cytoplasm ratio, and fine granules and vacuoli.

Mouse heart EC isolation. Mouse heart ECs (MHECs) were isolated and cultured from 7-day-old mice (54). Briefly, harvested tissues were digested with collagenase (Worthington Biochemical Corp.), and ECs were isolated with 2 rounds of magnetic bead purification (Invitrogen), the first with anti-PECAM- 1 and the second with anti-ICAM-2 mAb (BD Biosciences).

Monocyte adhesion under defined laminar flow conditions. Monocytes from blood of $\mathrm{apoE}^{+/+}$and apoE-/- mice were isolated. Interactions with MHECs were examined under conditions of fluid shear stress in a parallel plate flow chamber (55). Briefly, confluent MHECs were grown on glass coverslips (25-mm diameter; Carolina Biological Supply Co.) coated with $5 \mu \mathrm{g} / \mathrm{ml}$ fibronectin (Sigma-Aldrich), stimulated with $120 \mathrm{ng} / \mathrm{ml} \mathrm{TNF}-\alpha$ for 4 hours, and inserted into the flow chamber. Monocytes $\left(10^{5}\right.$ cells) were suspended in flow buffer (Dulbecco PBS, $0.75 \mathrm{mM} \mathrm{Ca}^{2+}$ and $\mathrm{Mg}^{2+}$, containing $0.1 \%$ human serum albumin) and drawn through the flow chamber as a bolus at an estimated shear stress of 0.76 dynes $/ \mathrm{cm}^{2}$. Monocyte accumulation was measured after 3 minutes of flow by counting stably adherent monocytes in 12-16 different fields. Monocyte-MHEC interactions were viewed using videomicroscopy $(\times 20$ phase-contrast objective) and digitally recorded to a PC using VideoLab software (version 2.2.1; Ed Marcus Laboratories).

Immunobistochemistry. Aortas were excised, frozen in O.C.T. compound (Sakura), sectioned in $5-\mu \mathrm{m}$ slices, and stained by the avidin-biotin-peroxidase method as previously described (56). Cell types were identified with primary antibodies: monoclonal anti-CD31 (MEC 13.3) for endothelial cells, rat anti-mouse Mac-3 (M3/84) for macrophages, and anti-Ly-6C (AL-21) antibody to mouse macrophage precursor cells (BD Biosciences). Images were captured with a digital camera (Nikon DXM1200F) using imaging software ACT-1 (version 2.63; Nikon).

In vivo accumulation. Purified Ly-6Chi or Ly- $6 \mathrm{C}^{\text {lo }}$ monocytes from the spleen of apoE $\mathrm{E}^{-/-}$or apoE $\mathrm{ap}^{-/-} \mathrm{CCR2} /-$ mice were injected into apoE CD $45.1^{+/+}$mice or labeled with [ ${ }^{111}$ In] oxine according to the manufacturer's protocol (Amersham Biosciences). For imaging and autoradiography experiments, cells were washed with HBSS, spun, and resuspended in $\left[{ }^{111} \mathrm{In}\right]$ oxine for 15 minutes at $37^{\circ} \mathrm{C}, \mathrm{pH}$ 6.5-7.5. The cells were then washed twice with HBSS. This labeling protocol keeps the cells viable and in a resting state (16). Approximately $0.8 \times 10^{6}$ cells incorporating $50 \mu \mathrm{Ci}$ were injected i.v. into apoE $\mathrm{E}^{-/-}$mice fed Western diet for 50 weeks. The total amount of activity that was injected into each animal was measured with a radioisotope calibrator (Capintec Inc.). For flow cytometric studies, approximately $4 \times 10^{6} \mathrm{Ly}-6 \mathrm{C}^{\text {hi }} \mathrm{CD} 45.2$ monocytes were injected to $\mathrm{CD} 45.1^{+/+}$apoE $\mathrm{E}^{-/-}$mice fed Western diet for 50 weeks. After 24 hours, all animals were euthanized with $\mathrm{CO}_{2}$. Aortas were perfused in situ with $10 \mathrm{ml} \mathrm{HBSS}$ via the left ventricle and excised from the root to the bifurcation. All heart and fat tissue was excised to eliminate confounding signal. Aortas were then subjected to digestion (flow cytometric studies, see above). For radioactive studies, cpm for each aorta as well as blood were measured using a Wallac 1480 WIZARD gamma counter (PerkinElmer). Percent injected dose per gram tissue was calculated after correcting for 
decay, excretion, and tail radioactivity from occasional subtle extravasations. Digital autoradiography was used with high-sensitivity screens and $50 \mu \mathrm{m}$ readout (Phosphorimager Screen; Molecular Dynamics; GE HealthCare) for visualization of the spatial distribution of isotopelabeled cells throughout the aorta. Accumulation was normalized to relative contribution of Ly-6Chi and Ly-6C $\mathrm{Clo}^{\text {lo }}$ monocytes in blood of apoE $\mathrm{E}^{-/-}$ mice fed Western diet.

Serum cholesterol measurement. At the time of sacrifice, blood was obtained by retroorbital bleeding. Serum was obtained by centrifugation at $16 \mathrm{~g}$ for 15 minutes at $37^{\circ} \mathrm{C}$. Serum cholesterol levels were measured using a cholesterol kit (Hemagen Diagnostics Inc.).

Statistics. Data are expressed as mean \pm SEM. Statistical tests included unpaired, 2-tailed Student's $t$ test using Welch's correction for unequal variances and 1-way ANOVA with Tukey's multiple comparison test. Statistical analyses were done using Prism. A $P$ value of 0.05 or less was considered to be significant.

\section{Acknowledgments}

This work was supported in part by the Donald W. Reynolds Cardiovascular Clinical Research Center at Harvard Medical School (to R. Weissleder and P. Libby) and by NIH grants R24
CA69246, U01 HL080731, and P01-A154904 (to R. Weissleder); R01HL034636 (to P. Libby); and HL53393 and HL36028 (to F.W. Luscinskas). F.K. Swirski is supported by a postdoctoral fellowship from the American Heart Association (0525866T). M.J. Pittet is supported by the Human Frontier Science Program Organization (LT00369/2003). The authors would like to thank Barrett Rollins, Andrew Luster, and Israel Charo for providing CCR2-/- mice as well as Timur Shtatland for help with statistical analysis, Todd Sponholtz for technical assistance with immunohistochemistry, Melissa Carlson for secretarial assistance, and Michael Waring for sorting cells (all at Massachusetts General Hospital and Harvard Medical School).

Received for publication August 2, 2006, and accepted in revised form October 24, 2006.

Address correspondence to: Mikael J. Pittet, Center for Molecular Imaging Research, Massachusetts General Hospital, Harvard Medical School, 13th Street, Building 149, Room 5403, Charlestown, Massachusetts 02129, USA. Phone: (617) 726-5788; Fax: (617) 726-5708; E-mail: mpittet@hms.harvard.edu.
1. Hansson, G.K., and Libby, P. 2006. The immune response in atherosclerosis: a double-edged sword. Nat. Rev. Immunol. 6:508-519.

2. Libby, P. 2002. Inflammation in atherosclerosis. Nature. 420:868-874.

3. Ridker, P.M., Hennekens, C.H., Buring, J.E., and Rifai, N. 2000. C-reactive protein and other markers of inflammation in the prediction of cardiovascular disease in women. N. Engl. J. Med. 342:836-843.

4. Peter, K., et al. 1997. Circulating vascular cell adhesion molecule- 1 correlates with the extent of human atherosclerosis in contrast to circulating intercellular adhesion molecule-1, E-selectin, P-selectin, and thrombomodulin. Arterioscler. Thromb. Vasc. Biol. 17:505-512.

5. Barron, H.V., Cannon, C.P., Murphy, S.A., Braunwald, E., and Gibson, C.M. 2000. Association between white blood cell count, epicardial blood flow, myocardial perfusion, and clinical outcomes in the setting of acute myocardial infarction: a thrombolysis in myocardial infarction 10 substudy. Circulation. 102:2329-2334.

6. Cannon, C.P., McCabe, C.H., Wilcox, R.G., Bentley, J.H., and Braunwald, E. 2001. Association of white blood cell count with increased mortality in acute myocardial infarction and unstable angina pectoris. OPUS-TIMI 16 Investigators. Am. J. Cardiol. 87:636-639; A610.

7. Friedman, G.D., Klatsky, A.L., and Siegelaub, A.B. 1974. The leukocyte count as a predictor of myocardial infarction. N. Engl. J. Med. 290:1275-1278.

8. Sabatine, M.S., et al. 2002. Relationship between baseline white blood cell count and degree of coronary artery disease and mortality in patients with acute coronary syndromes: a TACTICS-TIMI 18 (Treat Angina with Aggrastat and determine Cost of Therapy with an Invasive or Conservative StrategyThrombolysis in Myocardial Infarction 18 trial) substudy. J. Am. Coll. Cardiol. 40:1761-1768.

9. Rothe, G., et al. 1996. Peripheral blood mononuclear phagocyte subpopulations as cellular markers in hypercholesterolemia. Arterioscler. Thromb. Vasc. Biol. 16:1437-1447.

10. Imhof, B.A., and Aurrand-Lions, M. 2004. Adhesion mechanisms regulating the migration of monocytes. Nat. Rev. Immunol. 4:432-444.

11. van Furth, R., and Cohn, Z.A. 1968. The origin and kinetics of mononuclear phagocytes. J. Exp. Med. 128:415-435.

12. Volkman,A.1970. The origin and fate of the monocyte.
Ser. Haematol. 3:62-92.

13. Lessner, S.M., Prado, H.L., Waller, E.K., and Galis, Z.S. 2002. Atherosclerotic lesions grow through recruitment and proliferation of circulating monocytes in a murine model. Am. J. Pathol. 160:2145-2155.

14. Rajavashisth, T., et al. 1998. Heterozygous osteopetrotic (op) mutation reduces atherosclerosis in LDL receptor- deficient mice. J. Clin. Invest. 101:2702-2710.

15. Kim, C.J., et al. 2000. Polymerase chain reactionbased method for quantifying recruitment of monocytes to mouse atherosclerotic lesions in vivo: enhancement by tumor necrosis factor-alpha and interleukin-1 beta. Arterioscler. Thromb. Vasc. Biol. 20:1976-1982.

16. Swirski, F.K., et al. 2006. Monocyte accumulation in mouse atherogenesis is progressive and proportional to extent of disease. Proc. Natl. Acad. Sci. U. S. A. 103:10340-10345.

17. Smith, J.D., et al. 1995. Decreased atherosclerosis in mice deficient in both macrophage colony-stimulating factor (op) and apolipoprotein E. Proc. Natl. Acad. Sci. U. S. A. 92:8264-8268.

18. Ginhoux, F., et al. 2006. Langerhans cells arise from monocytes in vivo. Nat. Immunol. 7:265-273.

19. Gordon, S., and Taylor, P.R. 2005. Monocyte and macrophage heterogeneity. Nat. Rev. Immunol. 5:953-964.

20. Tacke, F., et al. 2006. Immature monocytes acquire antigens from other cells in the bone marrow and present them to $T$ cells after maturing in the periphery. J. Exp. Med. 203:583-597.

21. Geissmann, F., Jung, S., and Littman, D.R. 2003. Blood monocytes consist of two principal subsets with distinct migratory properties. Immunity. 19:71-82.

22. Grage-Griebenow, E., Flad, H.D., and Ernst, M. 2001. Heterogeneity of human peripheral blood monocyte subsets. J. Leukoc. Biol. 69:11-20.

23. Passlick, B., Flieger, D., and Ziegler-Heitbrock, H.W. 1989. Identification and characterization of a novel monocyte subpopulation in human peripheral blood. Blood. 74:2527-2534.

24. Sunderkotter, C., et al. 2004. Subpopulations of mouse blood monocytes differ in maturation stage and inflammatory response. J. Immunol. 172:4410-4417.

25. Plump, A.S., et al. 1992. Severe hypercholesterolemia and atherosclerosis in apolipoprotein E-defi- cient mice created by homologous recombination in ES cells. Cell. 71:343-353.

26. Zhang, S.H., Reddick, R.L., Piedrahita, J.A., and Maeda, N. 1992. Spontaneous hypercholesterolemia and arterial lesions in mice lacking apolipoprotein E. Science. 258:468-471.

27. Clinton, S.K., et al. 1992. Macrophage colony-stimulating factor gene expression in vascular cells and in experimental and human atherosclerosis. Am.J. Pathol. 140:301-316.

28. Chen, Y.C., et al. 2005. Apolipoprotein E is required for cell proliferation and survival in ovarian cancer. Cancer Res. 65:331-337.

29. Grainger, D.J., Reckless, J., and McKilligin, E. 2004. Apolipoprotein E modulates clearance of apoptotic bodies in vitro and in vivo, resulting in a systemic proinflammatory state in apolipoprotein E-deficient mice. J. Immunol. 173:6366-6375.

30. Galkina, E., et al. 2006. Lymphocyte recruitment into the aortic wall before and during development of atherosclerosis is partially L-selectin dependent. J. Exp. Med. 203:1273-1282.

31. Nelken, N.A., Coughlin, S.R., Gordon, D., and Wilcox, J.N. 1991. Monocyte chemoattractant protein-1 in human atheromatous plaques. J. Clin. Invest. 88:1121-1127.

32. Yla-Herttuala, S., et al. 1991. Expression of monocyte chemoattractant protein 1 in macrophage-rich areas of human and rabbit atherosclerotic lesions. Proc. Natl. Acad. Sci. U. S. A. 88:5252-5256.

33. Guo, J., et al. 2003. Transplantation of monocyte CC-chemokine receptor 2-deficient bone marrow into ApoE3-Leiden mice inhibits atherogenesis. Arterioscler. Thromb. Vasc. Biol. 23:447-453.

34. Veillard, N.R., et al. 2005. Differential influence of chemokine receptors CCR2 and CXCR3 in development of atherosclerosis in vivo. Circulation. 112:870-878.

35. Gu, L., et al. 1998. Absence of monocyte chemoattractant protein-1 reduces atherosclerosis in low density lipoprotein receptor-deficient mice. Mol. Cell. 2:275-281.

36. Baigent, C., et al. 2005. Efficacy and safety of cholesterol-lowering treatment: prospective meta-analysis of data from 90,056 participants in 14 randomised trials of statins. Lancet. 366:1267-1278.

37. Ridker, P.M., et al. 2005. C-reactive protein levels and outcomes after statin therapy. N. Engl. J. Med. 352:20-28.

38. O'Keeffe, M., et al. 2003. Dendritic cell precursor 
populations of mouse blood: identification of the murine homologues of human blood plasmacytoid pre-DC2 and CD11c+ DC1 precursors. Blood. 101:1453-1459.

39. Witztum, J.L., and Steinberg, D. 1991. Role of oxidized low density lipoprotein in atherogenesis. J. Clin. Invest. 88:1785-1792.

40. Parhami, F., et al. 1993. Minimally modified low density lipoprotein-induced inflammatory responses in endothelial cells are mediated by cyclic adenosine monophosphate. J. Clin. Invest. 92:471-478.

41. Shi, W., Haberland, M.E., Jien, M.L., Shih, D.M., and Lusis, A.J. 2000. Endothelial responses to oxidized lipoproteins determine genetic susceptibility to atherosclerosis in mice. Circulation. 102:75-81.

42. Hamilton, J.A., et al. 1999. Oxidized LDL can induce macrophage survival, DNA synthesis, and enhanced proliferative response to CSF-1 and GM-CSF. Arterioscler. Thromb. Vasc. Biol. 19:98-105.

43. Hundal, R.S., et al. 2001. Oxidized low density lipoprotein inhibits macrophage apoptosis through activation of the PI 3-kinase/PKB pathway. J. Lipid Res. 42:1483-1491.

44. Hanninen, A., Jaakkola, I., Salmi, M., Simell, O., and Jalkanen, S. 1997. Ly-6C regulates endothelial adhesion and homing of CD8 $(+) \mathrm{T}$ cells by activating integrin-dependent adhesion pathways. Proc.
Natl. Acad. Sci. U. S. A. 94:6898-6903.

45. Jutila, M.A., et al. 1988. Ly-6C is a monocyte/macrophage and endothelial cell differentiation antigen regulated by interferon-gamma. Eur. J. Immunol. 18:1819-1826.

46. Pflugh, D.L., Maher, S.E., and Bothwell, A.L. 2002. Ly-6 superfamily members Ly-6A/E, Ly-6C, and Ly-6I recognize two potential ligands expressed by B lymphocytes. J. Immunol. 169:5130-5136.

47. Poston, R.N., and Hussain, I.F. 1993. The immunohistochemical heterogeneity of atheroma macrophages: comparison with lymphoid tissues suggests that recently blood-derived macrophages can be distinguished from longer-resident cells. J. Histochem. Cytochem. 41:1503-1512.

48. van der Wal, A.C., Becker, A.E., van der Loos, C.M., and Das, P.K. 1994. Site of intimal rupture or erosion of thrombosed coronary atherosclerotic plaques is characterized by an inflammatory process irrespective of the dominant plaque morphology. Circulation. 89:36-44.

49. Mantovani, A., Sica, A., and Locati, M. 2005. Macrophage polarization comes of age. Immunity. 23:344-346.

50. Mantovani, A., et al. 2004. The chemokine system in diverse forms of macrophage activation and polarization. Trends Immunol. 25:677-686.
51. Afiune Neto, A., Mansur Ade, P., Avakian, S.D., Gomes, E.P., and Ramires, J.A. 2006. Monocytosis is an independent risk marker for coronary artery disease [In Portuguese]. Arq. Bras. Cardiol. 86:240-244.

52. Kleemann, R., et al. 2004. Evidence for anti-inflammatory activity of statins and PPARalpha activators in human C-reactive protein transgenic mice in vivo and in cultured human hepatocytes in vitro. Blood. 103:4188-4194.

53. Van Rooijen, N., and Sanders, A. 1994. Liposome mediated depletion of macrophages: mechanism of action, preparation of liposomes and applications. J. Immunol. Methods. 174:83-93.

54. Lim, Y.C., et al. 2003. Heterogeneity of endothelial cells from different organ sites in T-cell subset recruitment. Am. J. Pathol. 162:1591-1601.

55. Luscinskas, F.W., et al. 1994. Monocyte rolling, arrest and spreading on IL-4-activated vascular endothelium under flow is mediated via sequential action of L-selectin, beta 1-integrins, and beta 2 integrins. J. Cell Biol. 125:1417-1427.

56. Aikawa, E., et al. 2006. Human semilunar cardiac valve remodeling by activated cells from fetus to adult: implications for postnatal adaptation, pathology, and tissue engineering. Circulation. 113:1344-1352. 